\title{
Cytokines derived from innate lymphoid cells assist Helicobacter hepaticus to aggravate hepatocellular tumorigenesis in viral transgenic mice
}

\author{
Xiao Han ${ }^{1}$, Tianren Huang ${ }^{1}$ and Junqing $\operatorname{Han}^{2^{*}}$
}

\begin{abstract}
Background: Recently, intestinal microbiome has been involved in hepatic diseases due to the immunologic and metabolic communication between liver and intestine. Initiation of hepatocellular carcinoma (HCC) frequently attributes to conspiracy between immune cells and infectious carcinogens. Here, the hypothesis that the tumorigenesis of HCC with HBV infection will be aggravated by specific intestinal bacteria was verified in viral transgenic mouse models.

Methods: Comparative $16 \mathrm{~S}$ rRNA sequencing was adopted to observe the intestinal enrichment of Helicobacter hepaticus in HCC. Oral administration of Helicobacter hepaticus was carried out to evaluate its hepatic carcinogenic effect in HBV transgenic mice or wildtype C57BL/6. The livers of experimental mice were collected and examined for the degree of tumorigenesis.

Results: We found that Helicobacter hepaticus more likely colonized at lower colon of HBV-infected mice with HCC, compared with C57BL/6 and HBV-infected mice without neoplasm. Pretreatment of Helicobacter hepaticus in transgenic mice aggravated tumor formation, with higher incidence, more tumor nodule and higher serum AFP. Then, a cytokines expression patterns with inclined IFN- $\gamma$, IFN- $\gamma R$ R, IL-17 and IL-23 was found in HBV-infected mice with Helicobacter hepaticus. Furthermore, innate lymphoid cells, especially Th17 and NK cells which can secret IL-17 and IFN- $\gamma$ respectively, might be recruited by Helicobacter hepaticus cooperated with HBV. Besides, increased expression of CD69, NKG2D and IFN- $\gamma$ showed activation of cytokine production in intrahepatic NK cells. Finally, IFN- $\gamma$ decreased E-cadherin expression through p-STAT1 pathway, resulting in epithelial-mesenchymal transition with inclined expression of Snail2, SIP1 and CXCR4 in vitro. P-STAT1 inhibitor was able to reverse the expression of E-cadherin and EMT resulted from IFN- $\gamma$ function on $\mathrm{HBsAg}$-positive hepatocytes.
\end{abstract}

Conclusions: Helicobacter hepaticus generate a detrimental immune microenvironment by IFN- $\gamma / \mathrm{p}-\mathrm{STAT} 1$ axis which can promote the tumorigenesis of hepatitis B via recruiting innate lymphoid cells.

Keywords: Helicobacter hepaticus, Hepatitis B virus, Hepatocellular carcinoma, Innate lymphoid cells, IFN- $\gamma / p-S T A T 1$ axis

\footnotetext{
*Correspondence: hanjunqing1960@126.com

2 Department of Tumor Research and Therapy Center, Shandong

Provincial Hospital Affiliated to Shandong University, 324\# Jingwu Road,

Jinan 250021, China

Full list of author information is available at the end of the article
}

(c) The Author(s) 2019. This article is distributed under the terms of the Creative Commons Attribution 4.0 International License (http://creativecommons.org/licenses/by/4.0/), which permits unrestricted use, distribution, and reproduction in any medium, provided you give appropriate credit to the original author(s) and the source, provide a link to the Creative Commons license, and indicate if changes were made. The Creative Commons Public Domain Dedication waiver (http://creativecommons.org/ publicdomain/zero/1.0/) applies to the data made available in this article, unless otherwise stated. 


\section{Introduction}

In accordance with latest statistics, hepatocellular carcinoma (HCC) is the third cause of cancer death in the world [1]. Hepatitis B virus (HBV) infection is associated with at least $55 \%$ incidence of cirrhosis, followed by hepatic functional decompensation leading to initiation of HCC [2]. Nowadays, progression of HCC can be significantly restrained by viral polymerase inhibition from nucleotide analogues drugs [3], however, hepatic cancer risk of patients with long-duration HBV infection can remain above normal after functional clearance of the virus infection [4-6]. This clinical problem indicated that some viral integration mechanisms resulting in genomic changes render hepatic carcinogenesis, including chromosomal instability $[7,8]$, and function regulation of human telomerase reverse transcriptase gene [9]. Moreover, investigators believed that incontrollable inflammation and liver remodeling are highly relative to antiviral immunity $[10,11]$, considering HBV itself is non-cytopathic to host cells. Therefore, the immune against viral integrated-hepatocytes is vital in the pathogenesis of HBV-associated HCC.

Recently a study demonstrated that intestinal Lactobacillus gasseri triggered the production of interleukin 17 by intrahepatic $\gamma \delta \mathrm{T}$ cells, resulting in cholestatic hepatitis [12]. It seems a few strains with disrupted intestinal barriers can participate in pathogenesis of hepatic disease, including hepatocellular carcinoma, by regulating innate lymphoid cells (ILCs) and their inflammatory chemokines [13-15]. Manipulating intestinal microbiome in mice induced CXCL16 expression of liver sinusoidal endothelial cells, which accumulated $\mathrm{CXCR6}^{+}$natural killer $\mathrm{T}$, reinforcing an antitumor effect by interferon- $\gamma$ secretion [16]. Evidences for the connection between intestinal microflora and HCC gradually rise, however, few study has investigated the role of specific strains in development of HCC taking viral etiology into consideration. In our study, we used HBV transgenic mice to simulate the course of human HCC, to verify the hypothesis that Helicobacter hepaticus, a specific strain highly relative to hepatitis, could facilitate the carcinogenesis of HBV infected hepatitis via regulating innate lymphoid cells.

\section{Results}

Helicobacter hepaticus are over-presented in feces from mice with HBV infected HCC

Considering the concentrated Helicobacter spp. and its carcinogenesis in colorectal cancer [17, 18], we studied whether Helicobacter hepaticus in intestine involved in neoplastic development via enterohepatic crosstalk among natural HBs-Tg mice. We analyzed $H$. hepaticus level in feces from the mice at 24-25-month-old with an incidence of $40 \%$ for neoplasia as previous studies [19]. H. hepaticus was concentrated in feces from mice with hepatic carcinoma compared with that from purely HBV infection $(\mathrm{P}<0.01)$ (Fig. 1a). Based on the median value of $H$. hepaticus level in feces, the cancerous group was divided into high $(\mathrm{n}=6)$ and low $(\mathrm{n}=6)$ abundance group (Fig. 1b). The relation between $H$. hepaticus abundance and the serological hepatic patterns are evaluated. Results showed that higher enrichment of $H$. hepaticus is more likely associated with advanced HCC (ALT P $<0.05$, AFP $\mathrm{P}<0.05$ ) (Fig. 1c). Moreover, no difference of $H$. hepaticus abundance in the liver was observed between HBV-associated hepatitis and hepatocarcinoma $(\mathrm{P}>0.05)$ (Fig. 1d). S16RNA qPCR analysis to tissues revealed that $H$. hepaticus more likely over-presented at lower colon than higher one $(\mathrm{P}<0.01)$ (Fig. 1e). These data suggest that $H$. hepaticus accumulate at the lower colon of HBV infected HCC, which indicate the H. hepaticus involvement may aggravate the tumorigenesis of HBV-associated hepatitis without leaving the intestinal.

\section{Helicobacter hepaticus potentiated hepatocellular tumorigenesis in HBV-transgenic mice}

We had observed that $H$. hepaticus enriched in intestinal were associated with not only the development of HBV-infected HCC, but advanced tumor. For defining whether $H$. hepaticus can accelerate viral hepatic tumorigenesis, we performed oral introduction of $H$. hepaticus in HBV transgenic mice. 4-5-monthold HBs-Tg mice were gavaged with $H$. hepaticus strain for 8 months (Fig. 2a). When all mice reached 13 months old, HBs-Tg mice with $H$. hepaticus administration involved in hepatic neoplasia development with a higher incidence (100\%), more tumor nodules $(\mathrm{P}<0.01)$ and higher serum AFP $(\mathrm{P}<0.01)$, compared to wild type $\mathrm{B} 6$ with or without $H$. hepaticus and

\footnotetext{
(See figure on next page.)

Fig. 1 Helicobacter hepaticus are over-presented in feces from mice with HBV infected HCC. a Abundance of fecal $H$. hepaticus from the control $(\mathrm{C} 57 \mathrm{BL} / 6)(\mathrm{n}=18), \mathrm{HBs}-\mathrm{Tg}$ mice without neoplasm $(\mathrm{n}=18)$, and mice with HBV infected HCC $(\mathrm{n}=12)$. b Division of H. hepaticus abundance into high $(n=6)$ and low $(n=6)$ basing on the median value. c Comparison of serum ALT, AFP activity between low and high level of fecal $H$. hepaticus in HBs-Tg mice with HCC. $\mathbf{d}$ Abundance of hepatic H. hepaticus from the control (C57BL/6) $(n=18)$, HBs-Tg mice without neoplasm ( $\mathrm{n}=18)$, and mice with HBV infected HCC $(n=12)$. e Comparison of $H$. hepaticus abundance between lower and higher colon in HBs-Tg mice with HCC. Data are expressed as median \pm percentile. Mann-Whitney $U$ was used. $P<0.05$ represents statistical difference. ${ }^{*} P<0.05$, ${ }^{* *} P<0.01$
} 

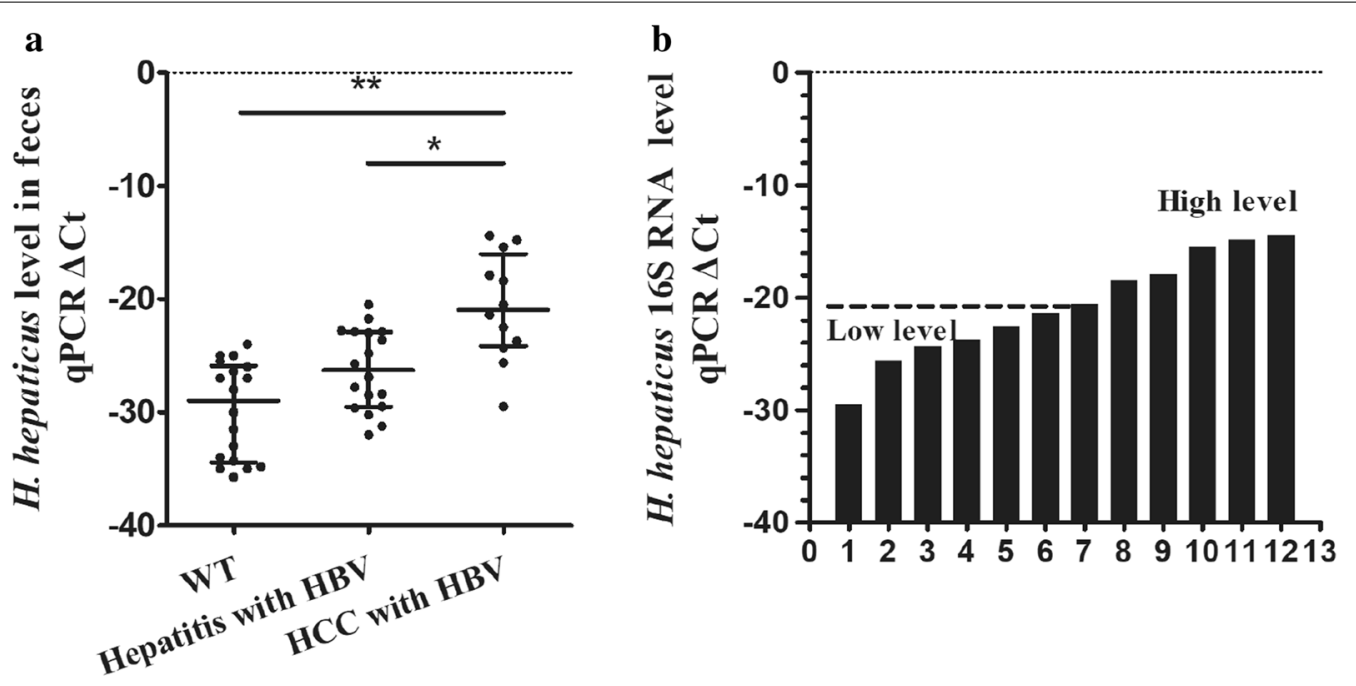

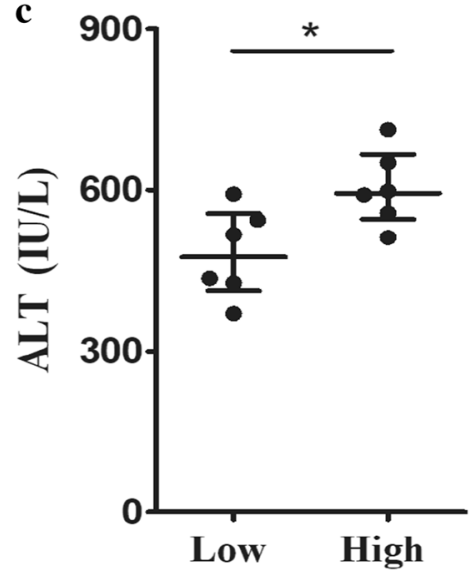

The level of $H$. hepaticus

d



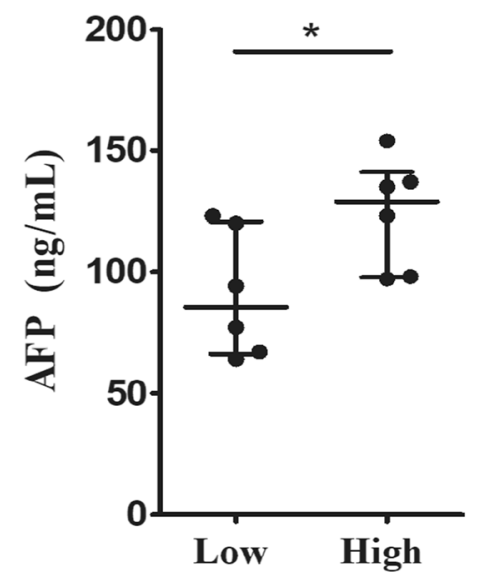

The level of $H$. hepaticus

e






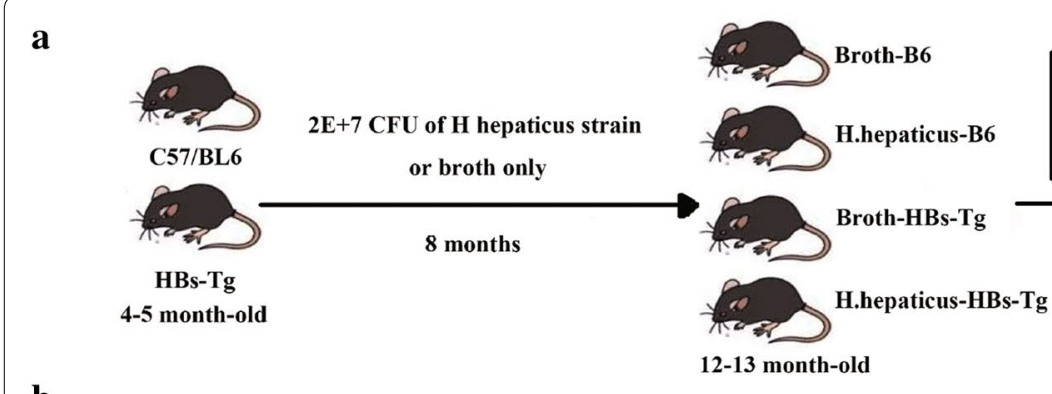

b



d


f

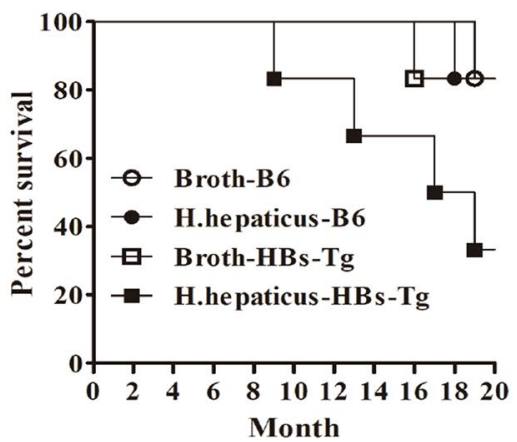

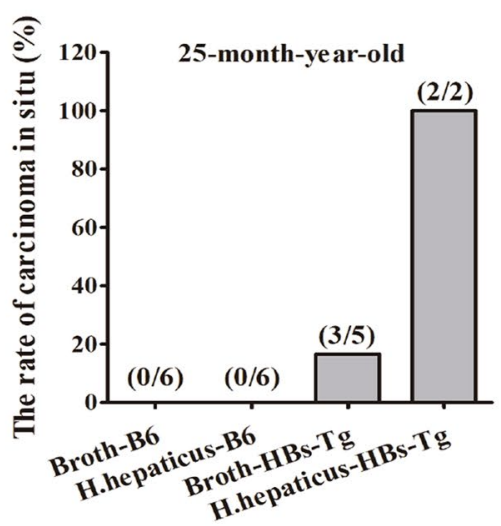

c



e
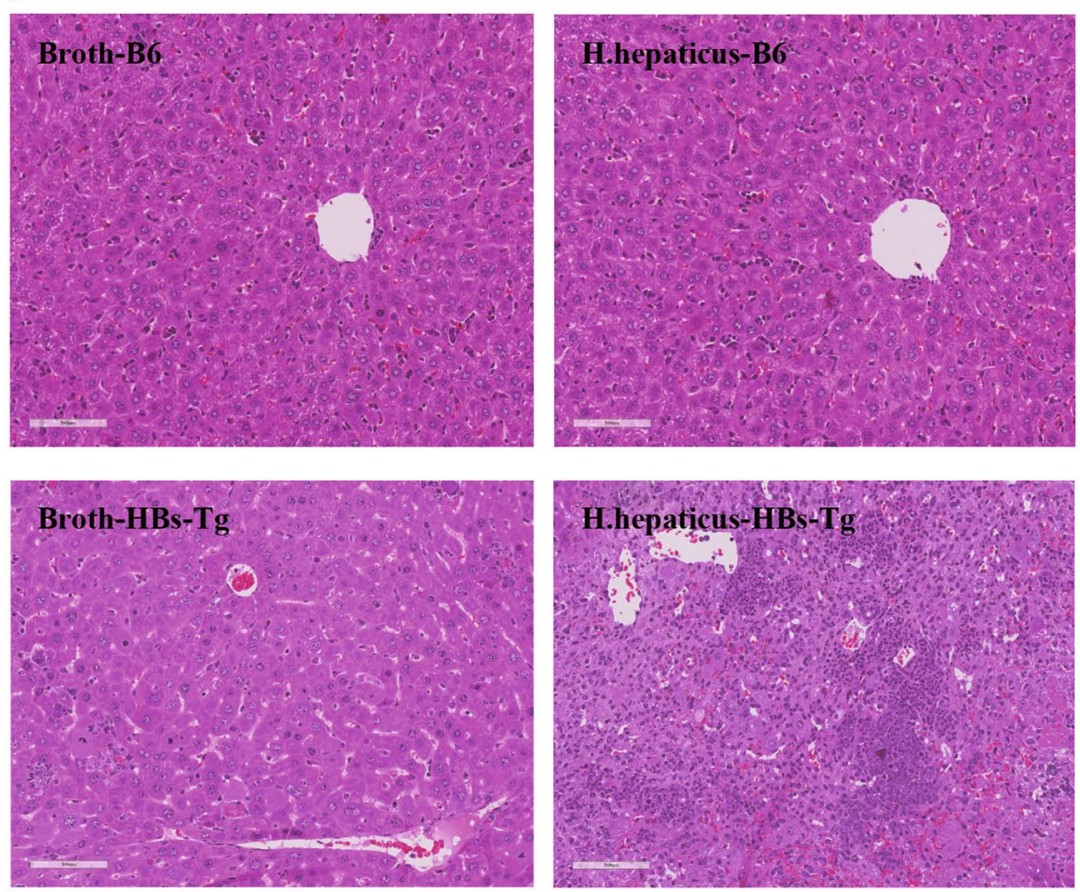

Fig. 2 Helicobacter hepaticus potentiated hepatocellular tumorigenesis in HBV-transgenic mice. a Experimental protocol. H. hepaticus (2 × $10^{7}$ CFU) was gavaged into 4-5-month-old HBs-Tg and B6 mice every $48 \mathrm{~h}$ for 8 months. b Tumorigenesis incidence in each group ( $\mathrm{n}=6$ ). $\mathbf{c}$ Liver tumor nodule numbers in each group $(n=6)$. $\mathbf{d}$ Serum AFP activity for each group $(n=6)$. e Representative H\&E sections of livers in each group at 13 months old. f Survival of each group $(n=6)$. Data are expressed as median \pm percentile. Mann-Whitney $U$ and Log-rank (Mantel-Cox) test was used respectively. $P<0.05$ represents statistical difference. ${ }^{*} P<0.05$, ${ }^{* *} P<0.01$ 
HBs-Tg mice (Fig. 2b-d). Hepatic histological sections exhibited, trabecular HCC with classical lobule in cirrhosis more likely appeared in HBs-Tg mice fed $H$. hepaticus, compared with the other groups (Fig. 2e) confirming the hepatocarcinoma in microcosmic. Then, neither wild type HBs-Tg mice nor wild type B6 (with or without $H$. hepaticus) at 24-25-month-old showed higher incidence for neoplasia than those HBs$\mathrm{Tg}$ mice after $H$. hepaticus introduction (Fig. 2b), the survival of which was shorter than those of the other groups $(\mathrm{P}<0.01)$ (Fig. 2f). Taken together, these results suggest that $H$. hepaticus can accelerate the tumorigenesis of HBV-infected hepatitis in transgenic mice.

\section{ILC-derived cytokines contribute to helicobacter hepaticus-associated HCC development in HBs-Tg mice}

It is believed that inflammatory injury of liver furthers the initiation of malignant neoplasm via inflammatory cells and their chemkines. ILCs can aggravate epithelial-mesenchymal transition during tumor progression by up-regulating inflammatory cytokines [20]. Therefore, we evaluated the cytokines expression patterns in hepatic microenvironment. We detected most cytokines which defense against viral infections (Fig. 3a and Additional file 1: Figure S1A). Significant incline in IFN- $\gamma$, IFN- $\gamma$ R1, IL-17 and IL-23 gene expression were found in HBs-Tg mice with $H$. hepaticus $(\mathrm{P}<0.05)$ (Fig. 3a). To elucidate whether the tumorigenesis of HBV-infected hepatitis could attribute to ILCs recruited by $H$. hepaticus introduction, we characterized the infiltrating immune cells of livers in wild type B6 mice with or without $H$. hepaticus, HBs-Tg mice alone and HBs-Tg mice with $H$. hepaticus at the same time (Additional file 1: Figure S1B). NK and NKT cells, but not $\mathrm{T}$ cells, were enriched in the liver of HBs-Tg mice with $H$. hepaticus ( $\mathrm{T}$ cells, $\mathrm{P}>0.05$; NKT cells, $\mathrm{P}<0.05$; NK cells, $\mathrm{P}<0.01$ ) (Fig. $3 \mathrm{~b}$ ). Considering the expression patterns of inflammatory fators, we more likely concerned about IFN- $\gamma$ and IL-17 secreted ILCs. Then we found that, compared with the other groups, Th17 increased to a more extent in HBs-Tg mice with $H$. hepaticus introduction $(\mathrm{P}<0.05)$ (Fig. $3 \mathrm{c}$ ), while hepatic NKT cells of which were enriched without sustained increase in IL-17 and IFN- $\gamma$ expression $(\mathrm{P}>0.05)$ (Fig. 3d). Besides, increased expression of CD69, NKG2D and IFN- $\gamma$ showed activation of cytokine production in intrahepatic NK cells in HBs-Tg mice with $H$. hepaticus (all $\mathrm{P}<0.01$ ), but not FasL, TRAIL and CD107a (all P >0.05) (Fig. 3e). These results indicated that some specific ILCs activated by $H$. hepaticus may exacerbate tumorigenesis via IL-17 and IFN- $\gamma$ in HBVassociated HCC.

\section{ILC-derived IFN- $\gamma$ triggered epithelial-mesenchymal transition via STAT1 signaling in Helicobacter hepaticus-associated HCC}

We further explored the molecular mechanism of ILCderived IFN- $\gamma$ on the tumorigenesis. The expression of E-cadherin in pure HBsTg mice gradually decreased with age $(\mathrm{P}<0.05)$ (Fig. 4a), whereas, higher significantly than that in HBsTg mice with $H$. hepaticus at 13 months $(\mathrm{P}<0.05)$ (Fig. 4b). IFN- $\gamma$ antibody treatment significantly reversed the decrease of E-cadherin $(\mathrm{P}<0.05)$ (Fig. 4b) indicated that the E-cadherin related carcinogenesis effect of $H$. hepaticus on HBs-Tg mice depended on the presence of IFN- $\gamma$. Moreover, the expression of Snail 2, SIP1 and CXCR4 was up-regulated in HBsAg-positive hepatocytes $96 \mathrm{~h}$ after IFN- $\gamma$ stimulation in vitro (mRNA Fig. 4 d, protein Fig. 4 e, $\mathrm{P}<0.05$ ), with higher amount of p-STAT1, but not p-STAT3 (Fig. 4c). The p-STAT1 inhibitor (fludarabine) significantly reversed the change of E-cadherin, Snail2, SIP1 and CXCR4 in IFN- $\gamma$-treated HBsAg-positive hepatocytes (mRNA Fig. 4d, protein Fig. $4 \mathrm{e}, \mathrm{P}<0.05)$. The level changes of $\mathrm{p}$-STAT1 protein manifested the inhibition efficiency of fludarabine in Fig. 4e. Collectively, all these data suggested ILC-derived IFN- $\gamma$ repressed E-cadherin by p-STAT1 up-regulation in Helicobacter hepaticus-associated HCC.

\section{Discussion}

Helicobacter species contribute to several kinds of chronic inflammation and carcinoma in mice. In spite of the presence of specific helicobacter strains were proved in human liver cancer, the pathogenic role of Helicobacter species on hepatic diseases remains undefined. $H$. hepaticus related injury and carcinogenesis in hepatocytes by activating nuclear factor-kB-regulated networks associated with innate and $\mathrm{T}$ helper 1-type adaptive immunity in aflatoxin B1 induced murine model of HCC [17]. However, few study investigated the involvement of H. hepaticus in HBV-associated HCC. In recent study, transgenic mice model with viral hepatitis mimical period were utilized to uncover the over-presented $H$. hepaticus was significantly related to the initiation of cirrhosis and neoplasm development in liver (Figs. 1 and 2). Moreover, our study indicated that $H$. hepaticus accumulation might result in the rising of the triggered anti-virus cytokines via ILCs (Fig. 3).

Hepatitis and infiltration of immune cells in $H$. hepaticus-infected cancer indicated that chronic inflammation may make primary contribution to the promotion for carcinogenesis [21]. Recruited to the liver in chronic $H$. hepaticus infected mice, plenty of neutrophils and macrophages in microenvironment accumulated oxidized nucleoside 8-hydroxydeoxyguanosine in hepatocytes by 


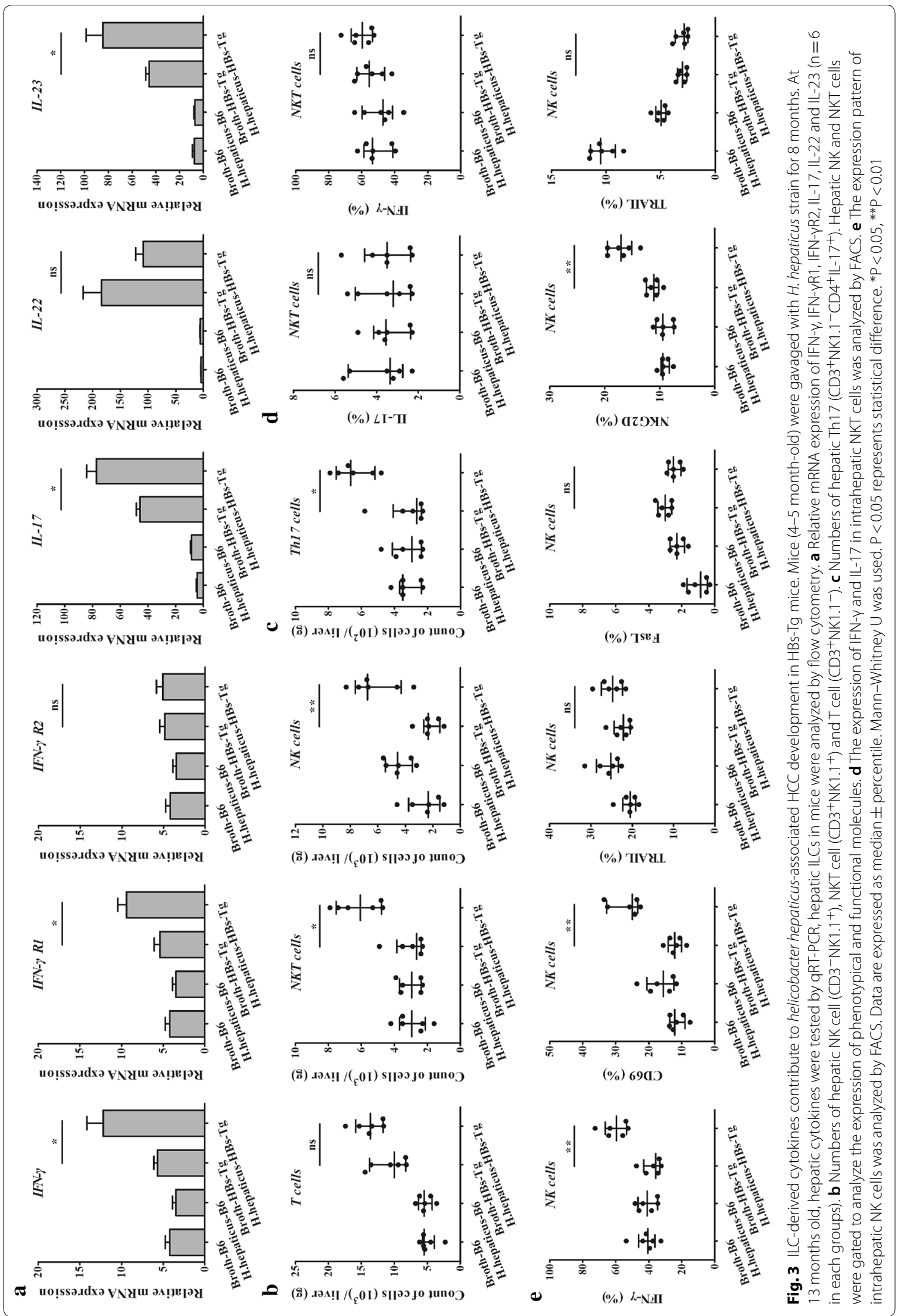




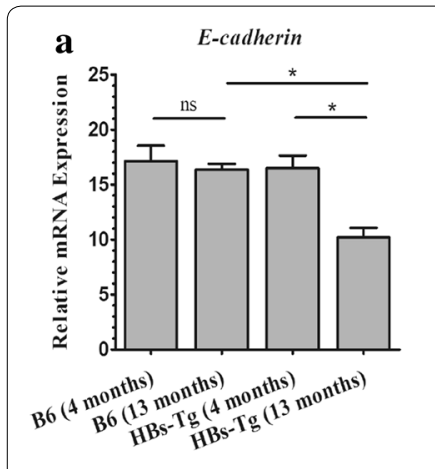

d

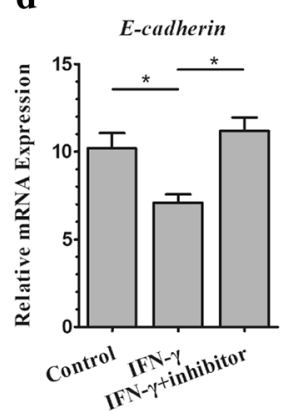

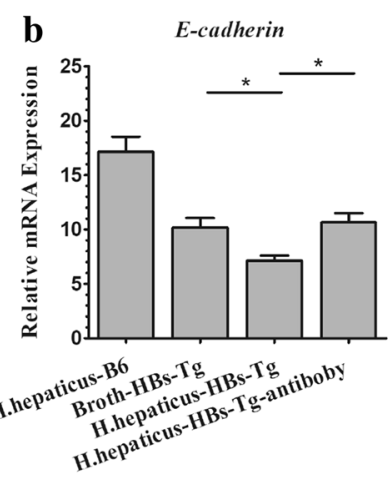

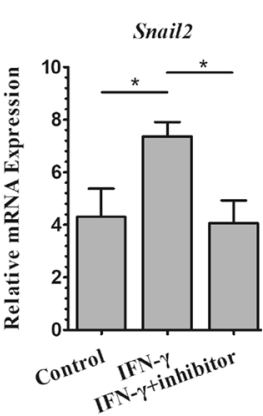

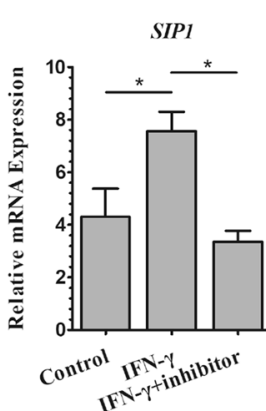


Fig. 4 ILC-derived IFN- $y$ triggered epithelial-mesenchymal transition via STAT1 signaling in Helicobacter hepaticus-associated HCC. a Hepatic E-cadherin relative expression at different ages in wild type $\mathrm{B} 6$ and $\mathrm{HBs}$-Tg. $\mathbf{b}$ Hepatic E-cadherin relative expression in $\mathrm{H}$. hepaticus adopted HBs-Tg mice with IFN- $\gamma$ antibody. c Hepatic signaling pathways detected by western blotting at 13 months old. $\mathbf{d}$ Detection of E-cadherin and EMT-related genes in primary hepatocytes with IFN- $\gamma$ and inhibitor. Data are expressed as median \pm percentile. Mann-Whitney $U$ was used. $P<0.05$ represents statistical difference. ${ }^{*} \mathrm{P}<0.05,{ }^{*} \mathrm{P}<0.01$

ROS secretion, exacerbating the hepatic tumorigenesis [22]. It seems that innate immunity against $H$. hepaticus is the major force attributing to this kind of inflammation [23]. Orogastric administration of $H$. hepaticus in $\mathrm{Rag} 2^{-/-} \mathrm{Apc}^{\mathrm{Min} /+}$ mice developed breast carcinoma, an extraintestinal tumor, in the absence of lymphocytes [24]. However, rare study has reported that NK cells can assist the malignant progress of hepatic tumors.

As we usually understood, both HCC in situ and colonic metastatic carcinoma in the liver could be restrained by phagocytosis from activated NK cells [25, 26]. In hepatitis B virus associated cancer, NK cells were guided by the cooperation between cancerous cells and virus to functionally promote $\mathrm{HCC}$ progression $[27,28]$. This kind of role transition in molecular mechanism had been proved as increasing of inhibitory receptor on NK cells including NKG2A, Tim3 and PD-1 [29, 30]. In our study, HBV infected hepatocyte damage was initialed by reprogrammed NK cells but not NKT cells, resulting in hepatic carcinoma.

Obviously, colonization of $H$. hepaticus aggravate liver cirrhosis and neoplasia in the liver with HBV infection in previous reports [31]. Our study represents the original investigation of the intestinal microbiome in hepatic carcinogenesis without over-presentation at hepatocytes (Fig. 1). It more likely involved cytokines release reacted to $H$. hepaticus from mesenteric lymph nodes towards microenvironment in the liver. Some studies demonstrated that $H$. hepaticus associated inflammation activated innate and Th1-type adaptive immunity with inclining expression of cytokines and receptors within the intestinal lymphatic system [32].

Our study shows that $H$. hepaticus conspires with HBV to impair positive immunity of ILCs to accelerate progression of HCC. Although recent findings reveal the interaction between $H$. hepaticus, hepatic virus and liver in the evolution of HCC, further investigations are needed for novel prevention on HBV associated cancer in humans.

\section{Conclusion}

Helicobacter hepaticus generate a detrimental immune microenvironment by up-regulating ILCs. ILCs-derived IFN $-\gamma$ can promote the tumorigenesis of hepatitis B via E-cadherin/STAT1. 


\section{Materials and methods \\ Mice}

Ten-week-old male HBV transgenic mice C57BL/6J-TgN (AlblHBV) 44 Bri (named as HBs-Tg mice) were purchased from Department of Laboratory Animal Science of Peking University. The control C57BL/6J mice are the littermates of HBs-Tg mice. All mice were housed under specific pathogen-free conditions $\left(22{ }^{\circ} \mathrm{C}, 55 \%\right.$ humidity, and $12 \mathrm{~h}$ day/night rhythm). Feces, colons and livers in natural HBs-Tg mice would be collected for abundance evaluation of $H$. hepaticus at 24-25 months old. Besides, they were divided into four groups characterised by the presence or absence of the HBV transgene and $H$. hepaticus infection (shown as Fig. 1). Beginning at 4-5-monthold, mice were gavaged with $2 \times 10^{7}$ colony-forming units (CFU) of $H$. hepaticus strain or broth only every $48 \mathrm{~h}$ for 8 months as previously described [33]. Mice were euthanatised at $12-13$ or $24-25$-month-old by $\mathrm{CO}_{2}$ inhalation. Blood and livers were harvested at 12-13-month-old, submitted for histopathology, serum test, and quantitative real-time PCR (qRT-PCR). At 24-25-month-old, survival rate would be calculated.

\section{Bacterial strains}

Helicobacter hepaticus (type strain ATCC 51448) was cultured according to previously described [33]. Briefly, they grew under microaerobic conditions $\left(37^{\circ} \mathrm{C}\right)$ using trypticase soy blood agar (BD Biosciences, USA) at first, followed by inoculation in $5 \%$ fetal bovine serum-contained brucella broth on a rotary shaking incubator (Thermo Fisher Scientific, USA) for $48 \mathrm{~h}$. Then, the cultured broth was centrifuged at $10,000 \mathrm{rpm}\left(4{ }^{\circ} \mathrm{C}\right)$ for $20 \mathrm{~min}$. After harvested in exponential phase using OD600 nm test, the pellet was resuspended in brucella broth containing $30 \%$ glycerol, to approximately $10^{8}$ organisms $/ \mathrm{ml}$ as confirmed by spectrophotometry (MEGATOO, Beijing, China). Oral gavage of $0.2 \mathrm{ml}$ fresh culture was administrated into examed mice for three doses every 2 days, while medium alone was introduced into controls synchronously. Subculture of the inoculum and the medium on blood agar was used for maintaining the purity of the strain and the sterility of the medium.

\section{Serum biochemical assays}

Serum alanine aminotransferase (ALT), alpha-fetoprotein (AFP) was determined using ELISA kits (R\&D systems, Minneapolis, MN), according to the manufacturer's instructions.

\section{Preparation of fecal sample and colon tissues for PCR}

Based on the manufacturer's instructions, DNA in feces was extracted using the QIAamp DNA stool Mini Kit
(Qiagen, USA) with a spin column, followed by an elution in the Tris-EDTA buffer $(\mathrm{pH} 8)$. DNA of intestinal microbiome in situ was isolated from frozen colorectal tissues after mechanical homogenization (Tissue Lyser, Qiagen, USA), using the EZ1 DNA Tissue kit and the EZ1 BioRobot (Qiagen, USA). The parameter of the extracted DNA was measured by the NanoDrop 2000 spectrophotometer (Thermo Scientific, USA). All DNA samples were stored at $-80{ }^{\circ} \mathrm{C}$.

\section{Quantitative PCR}

All reactions were assayed in $20 \mu \mathrm{L}$ reaction volume containing $1 \times$ final concentration TaqMan Universal Master Mix (Applied Biosystems, USA) in a 96-well optical PCR plate. Each reaction contained $5 \mathrm{ng}$ of extracted faecal DNA and $5 \mu \mathrm{M}$ of primers. Amplification and detection of DNA was performed with the Roche Lightcycler 480 Quantitative Analysis System (Applied Biosystems). the following reaction conditions would be applied: $2 \mathrm{~min}$ at $50{ }^{\circ} \mathrm{C}, 10 \mathrm{~min}$ at $95^{\circ} \mathrm{C}$, and 40 cycles of $15 \mathrm{~s}$ at $95^{\circ} \mathrm{C}$ and $1 \mathrm{~min}$ at $60{ }^{\circ} \mathrm{C}$. The primers for detecting $H$. hepaticus and total bacteria were used as previously described [34]. The primers' sequences were as follows:

$H$. hepaticus forward primer, 5'-GCAUUUGAAACU GUUACUCUG-3';

Helicobacter hepaticus reverse primer, 5'-GGGGAG CUUGAAAACAG-3';

Total bacterial DNA forward primer, 5'-GCAGGCCTA ACACATGCAAGTC-3';

Total bacterial DNA reverse primer, $5^{\prime}$-CTGCTGCCT CCCGTAGGAGT-3'.

Every sample was assayed in triplicate in same batch, and the mean of these cycle threshold $(\mathrm{Ct})$ values was calculated for subsequent study. The relative abundance of $H$. hepaticus normalised to the total bacteria of each sample was calculated using the $2^{-\Delta \mathrm{Ct}}$ method (where $\Delta \mathrm{Ct}=$ the average $\mathrm{Ct}$ value of $H$. hepaticus in each sample-the average $C t$ value of total bacteria).

All primers of cytokines in livers were synthesized by Invitrogen (Thermo Fisher Scientific, USA), as shown in Additional file 1: Table S1. Results were analyzed using the $\Delta \Delta \mathrm{Ct}$ method and $\beta$-actin as the reference.

\section{Primary mouse hepatocyte isolation and culture}

Details are shown in supplementary materials and methods. The isolation and culture of primary mouse hepatocytes were performed as described [35]. IFN- $\gamma$ (PeproTech, USA) treatment was using $2 \mathrm{ng} / \mathrm{ml}$. STAT1 activity inhibition was done by incubation with $20 \mu \mathrm{M}$ Fludarabine (Selleckchem, USA) for $24 \mathrm{~h}$, followed by IFN- $\gamma$ treatment for another $24 \mathrm{~h}$. 


\section{Western blotting}

Details are shown in supplementary materials and methods. Liver tissues were lysed as described [35]. After SDS-PAGE, proteins were transferred onto PVDF membranes (Millipore Corporation, USA), and incubated with primary Abs over-night at $4{ }^{\circ} \mathrm{C}$. Membranes were washed with $0.1 \%$ (vol/vol) Tween 20 in TBS (pH 7.6) and incubated with a 1:2, 500 dilution of horseradish peroxidase-conjugated secondary Abs for 60 min at room temperature. Protein bands were visualized by ECL reaction (Pierce Biotechnology, Rockford, IL).

\section{Isolation of mononuclear cells in hepatic tumor}

Hepatic mononuclear cells were prepared as previously described [35]. Briefly, liver of mice was removed and washed with Ca and Mg free Dulbecco's Phosphate Buffered Saline (DPBS). After pressing through a 200-gauge stainless steel mesh, the cell mixture was resuspended in 40\% Percoll solution (General Electric Company, USA), followed by overlaying gently onto $70 \%$ Percoll solution. Then, this cell mixture was centrifuged at $1260 \times g$ for $30 \mathrm{~min}$ at room temperature. The interface cells between the percoll solutions were aspirated and washed twice with PBS medium. Single cell suspensions were resuspended in cell staining solution (PBS with $2 \%$ FCS) for flow cytometry.

\section{Multicolor flow cytometry analysis}

After Fc receptors blocking (BD Biosciences, USA), an appropriate concentration of the fluorescence-labeled antibody was used for the staining of surface antigens at $4{ }^{\circ} \mathrm{C}$ for $30 \mathrm{~min}$ in dark place. Fluorochromeconjugated monoclonal antibodies of cellular markers: PercpCy5.5-anti-CD3, FITC-anti-IL-17A, PE-anti-CD4, PE-Cy7-anti-NK1.1 (BD Bioscience, USA). FITC-antiCD69, FITC-anti-IFN- $\gamma$; PE-anti-FasL, PE-anti-TRAIL, PE-anti-CD107a, and APC-anti-NKG2D (eBioscience, San Diego, CA). The intracellular cytokine staining, including INF- $\gamma$ and IL-17A, was using Mouse Intracellular Cytokine Staining Starter Kit (BD Biosciences, USA), according to the kit's instructions. Samples were measured by a BD Accuri C6 plus flow cytometer (BD Biosciences, USA), and the data were managed using BD Accuri C6 plus analysis (BD Biosciences, USA).

\section{Statistical analysis}

All statistics were performed using GraphPad Prism 5.0 software (La Jolla, CA). Results of inflammatory genes, tumor number, ALT activity, AFP activity, cellular analysis, survival analysis and richness of bacteria were analyzed using Mann-Whitney U test, Log-rank
(Mantel-Cox) test as appropriate. Data are expressed as the medians with interquartile range. $\mathrm{P}<0.05$ was considered significant in comparison of medians.

\section{Additional file}

Additional file 1: Figure S1. Innate lymphoid cells contribute to helicobacter hepaticus-associated HCC development in HBs-Tg mice. Table S1. The primers for each gene detected by real-time PCR.

Acknowledgements

Not applicable.

\section{Authors' contributions}

$\mathrm{XH}$ performed the animal experiments and immunoassays, and was a major contributor in writing the manuscript. TH helped $\mathrm{XH}$ to analyzed the data of chemokines from livers. JH funded and directed all these researches and reviewed this manuscript. All authors read and approved the final manuscript.

\section{Funding}

The research and manuscript preparation are funded by Dr. Junqing Han.

\section{Availability of data and materials}

The datasets analyzed during the current study are available from the corresponding author on reasonable request.

\section{Ethics approval and consent to participate}

Not applicable.

\section{Consent for publication}

Not applicable.

\section{Competing interests}

The authors declare that they have no competing interests.

\section{Author details}

${ }^{1}$ Department of Experiment, Tumor Hospital Affiliated to Guangxi Medical University, 71\# Hedi Road, Nanning 530021, China. ${ }^{2}$ Department of Tumor Research and Therapy Center, Shandong Provincial Hospital Affiliated to Shandong University, 324\# Jingwu Road, Jinan 250021, China.

Received: 6 March 2019 Accepted: 27 April 2019

Published online: 15 May 2019

\section{References}

1. Bray F, Ferlay J, Soerjomataram I, Siegel RL, Torre LA, Jemal A. Global cancer statistics 2018: GLOBOCAN estimates of incidence and mortality worldwide for 36 cancers in 185 countries. CA Cancer J Clin. 2018;68(6):394-424. https://doi.org/10.3322/caac.21492.

2. Maucort-Boulch D, de Martel C, Franceschi S, Plummer M. Fraction and incidence of liver cancer attributable to hepatitis B and C viruses worldwide. Int J Cancer. 2018;142(12):2471-7. https://doi.org/10.1002/ijc.31280.

3. Singal AK, Salameh H, Kuo YF, Fontana RJ. Meta-analysis: the impact of oral anti-viral agents on the incidence of hepatocellular carcinoma in chronic hepatitis B. Aliment Pharm Ther. 2013;38(2):98-106. https://doi. org/10.1111/apt.12344.

4. Wong GLH, Tse YK, Yip TCF, Chan HLY, Tsoi KKF, Wong WWS. Long-term use of oral nucleos(t)ide analogues for chronic hepatitis B does not increase cancer risk-a cohort study of 44494 subjects. Aliment Pharm Ther 2017;45(9):1213-24. https://doi.org/10.1111/apt.14015.

5. Papatheodoridis GV, Idilman R, Dalekos GN, Buti M, Chi H, van Boemmel F, et al. The risk of hepatocellular carcinoma decreases after the first 5 years 
of entecavir or tenofovir in Caucasians with chronic hepatitis B. Hepatology. 2017;66(5):1444-53. https://doi.org/10.1002/hep.29320.

6. Yip TCF, Chan HLY, Wong VWS, Tse YK, Lam KLY, Wong GLH. Impact of age and gender on risk of hepatocellular carcinoma after hepatitis B surface antigen seroclearance. J Hepatol. 2017;67(5):902-8. https://doi. org/10.1016/j.jhep.2017.06.019.

7. Sung WK, Zheng HC, Li SY, Chen RH, Liu X, Li YR, et al. Genome-wide survey of recurrent HBV integration in hepatocellular carcinoma. Nat Genet. 2012;44(7):765. https://doi.org/10.1038/ng.2295.

8. Jiang ZS, Jhunjhunwala S, Liu JF, Haverty PM, Kennemer MI, Guan YH, et al. The effects of hepatitis B virus integration into the genomes of hepatocellular carcinoma patients. Genome Res. 2012;22(4):593-601. https://doi.org/10.1101/gr.133926.111.

9. Schluter V, Meyer M, Hofschneider PH, Koshy R, Caselmann WH. Integrated hepatitis-B virus- $X$ and $3^{\prime}$ truncated pres/S-sequences derived from human hepatomas encode functionally active transactivators. Oncogene. 1994;9(11):3335-44.

10. Tu T, Buhler S, Bartenschlager R. Chronic viral hepatitis and its association with liver cancer. Biol Chem. 2017;398(8):817-37. https://doi.org/10.1515/ hsz-2017-0118.

11. Tu T, Budzinska MA, Shackel NA, Jilbert AR. Conceptual models for the initiation of hepatitis B virus-associated hepatocellular carcinoma. Liver Int. 2015;35(7):1786-800. https://doi.org/10.1111/liv.12773.

12. Tedesco D, Thapa M, Chin CY, Ge Y, Gong MH, Li J, et al. Alterations in intestinal microbiota lead to production of interleukin 17 by intrahepatic gamma delta T-cell receptor-positive cells and pathogenesis of cholestatic liver disease. Gastroenterology. 2018;154(8):2178-93. https://doi. org/10.1053/j.gastro.2018.02.019.

13. Sandler NG, Koh C, Roque A, Eccleston JL, Siegel RB, Demino M, et al. Host response to translocated microbial products predicts outcomes of patients with HBV or HCV infection. Gastroenterology. 2011;141 (4):1220. https://doi.org/10.1053/j.gastro.2011.06.063.

14. Rahman K, Desai C, lyer SS, Thorn NE, Kumar P, Liu YS, et al. Loss of junctional adhesion molecule a promotes severe steatohepatitis in mice on a diet high in saturated fat, fructose, and cholesterol. Gastroenterology. 2016;151(4):733. https://doi.org/10.1053/j.gastro.2016.06.022.

15. Singh V, Yeoh BS, Chassaing B, Xiao X, Saha P, Olvera RA, et al. Dysregulated microbial fermentation of soluble fiber induces cholestatic liver cancer. Cell. 2018;175(3):679. https://doi.org/10.1016/j.cell.2018.09.004.

16. Ma C, Han MJ, Heinrich B, Fu Q, Zhang QF, Sandhu M, et al. MICROBIOME Gut microbiome-mediated bile acid metabolism regulates liver cancer via NKT cells. Science. 2018;360(6391):876. https://doi.org/10.1126/scien ce.aan5931.

17. Daniel SG, Ball CL, Besselsen DG, Doetschman T, Hurwitz BL. Functional changes in the gut microbiome contribute to transforming growth factor beta-deficient colon cancer. Msystems. 2017;2(5):e00065-17. https://doi. org/10.1128/msystems.00065-17.

18. Ge ZM, Feng Y, Ge LL, Parry N, Muthupalani S, Fox JG. Helicobacter hepaticus cytolethal distending toxin promotes intestinal carcinogenesis in 129Rag2-deficient mice. Cell Microbiol. 2017;19(7):e12728. https://doi. org/10.1111/cmi.12728.

19. Sunami Y, Ringelhan M, Kokai E, Lu M, O'Connor T, Lorentzen A, et al. Canonical NF-kappa B signaling in hepatocytes acts as a tumorsuppressor in hepatitis B virus surface antigen-driven hepatocellular carcinoma by controlling the unfolded protein response. Hepatology. 2016;63(5):1592-607. https://doi.org/10.1002/hep.28435.

20. Chen YY, Sun R, Jiang W, Wei HM, Tian ZG. Liver-specific HBsAg transgenic mice are over-sensitive to Poly(l: C)-induced liver injury in NK cell- and IFN-gamma-dependent manner. J Hepatol. 2007;47(2):183-90. https:// doi.org/10.1016/j.jhep.2007.02.020.

21. Li WY, Xiao J, Zhou X, Xu M, Hu CB, Xu XY, et al. STK4 regulates TLR pathways and protects against chronic inflammation-related hepatocellular carcinoma. J Clin Invest. 2015;125(11):4239-54. https://doi.org/10.1172/ Jci81203.

22. Sipowicz MA, Chomarat P, Diwan BA, Anver MA, Awasthi YC, Ward JM, et al. Increased oxidative DNA damage and hepatocyte overexpression of specific cytochrome $\mathrm{P} 450$ isoforms in hepatitis of mice infected with Helicobacter hepaticus. Am J Pathol. 1997;151(4):933-41.

23. Mandell L, Moran AP, Cocchiarella A, Houghton J, Taylor N, Fox JG, et al. Intact gram-negative Helicobacter pylori, Helicobacter felis, and Helicobacter hepaticus bacteria activate innate immunity via toll-like receptor 2 but not toll-like receptor 4. Infect Immun. 2004;72(11):6446-54. https://doi. org/10.1128/lai.72.11.6446.6454.2004.

24. Rao VP, Poutahidis T, Ge ZM, Nambiar PR, Horwitz BH, Fox JG, et al. Proinflammatory $\mathrm{CD} 4(+) \mathrm{CD} 45 \mathrm{RB}$ (hi) lymphocytes promote mammary and intestinal carcinogenesis in Apc(Min/+) mice. Cancer Res. 2006;66(1):5761. https://doi.org/10.1158/0008-5472.Can-05-3445.

25. Miyagi T, Takehara T, Tatsumi T, Kanto T, Suzuki T, Jinushi M, et al. CD1d-mediated stimulation of natural killer T cells selectively activates hepatic natural killer cells to eliminate experimentally disseminated hepatoma cells in murine liver. Int J Cancer. 2003;106(1):81-9. https://doi. org/10.1002/ijc.11163.

26. Dupaul-Chicoine J, Arabzadeh A, Dagenais M, Douglas T, Champagne C, Morizot A, et al. The Nlrp3 inflammasome suppresses colorectal cancer metastatic growth in the liver by promoting natural killer cell tumoricidal activity. Immunity. 2015;43(4):751-63. https://doi.org/10.1016/j.immun i.2015.08.013.

27. Zhang $Q F$, Yin WW, Xia Y, Yi YY, He QF, Wang $X$, et al. Liver-infiltrating CD11b(-)CD27(-) NK subsets account for NK-cell dysfunction in patients with hepatocellular carcinoma and are associated with tumor progression. Cell Mol Immunol. 2017;14(10):819-29. https://doi. org/10.1038/cmi.2016.28.

28. Yang YL, Han QJ, Hou ZH, Zhang C, Tian ZG, Zhang J. Exosomes mediate hepatitis B virus (HBV) transmission and NK-cell dysfunction. Cell Mol Immunol. 2017;14(5):465-75. https://doi.org/10.1038/cmi.2016.24.

29. Wolf MJ, Adili A, Piotrowitz K, Abdullah Z, Boege Y, Stemmer K, et al. Metabolic activation of Intrahepatic CD8(+) T cells and NKT Cells causes nonalcoholic steatohepatitis and liver cancer via cross-talk with hepatocytes. Cancer Cell. 2014;26(4):549-64. https://doi.org/10.1016/j.ccell 2014.09.003.

30. Wang J, Zhao WX, Cheng LA, Guo MZ, Li DL, Li XZ, et al. CD137-mediated pathogenesis from chronic hepatitis to hepatocellular carcinoma in hepatitis B virus-transgenic mice. J Immunol. 2010;185(12):7654-62. https ://doi.org/10.4049/jimmunol.1000927.

31. Dore MP, Realdi G, Mura D, Graham DY, Sepulveda AR. Helicobacter infection in patients with HCV-related chronic hepatitis, cirrhosis, and hepatocellular carcinoma. Digest Dis Sci. 2002;47(7):1638-43. https://doi. org/10.1023/A:1015848009444.

32. Myles MH, Dieckgraefe BK, Criley JM, Franklin CL. Characterization of cecal gene expression in a differentially susceptible mouse model of bacterial-induced inflammatory bowel disease. Inflamm Bowel Dis. 2007;13(7):822-36. https://doi.org/10.1002/ibd.20138.

33. Whary MT, Morgan TJ, Dangler CA, Gaudes KJ, Taylor NS, Fox JG. Chronic active hepatitis induced by Helicobacter hepaticus in the A/JCr mouse is associated with a Th1 cell-mediated immune response. Infect Immun. 1998;66(7):3142-8.

34. Shames B, Fox JG, Dewhurst F, Yan LL, Shen ZL, Taylor NS. Identification of widespread helicobacter-Hepaticus infection in feces in commercial mouse colonies by culture and PCR assay. J Clin Microbiol. 1995;33(11):2968-72.

35. Chen YY, Sun R, Wu XY, Cheng M, Wei HM, Tian ZG. CD4+CD25+ regulatory $T$ cells inhibit natural killer cell hepatocytotoxicity of hepatitis B virus transgenic mice via membrane-bound TGF-beta and OX40. J Innate Immun. 2016;8(1):30-42. https://doi.org/10.1159/000431150.

\section{Publisher's Note}

Springer Nature remains neutral with regard to jurisdictional claims in published maps and institutional affiliations. 